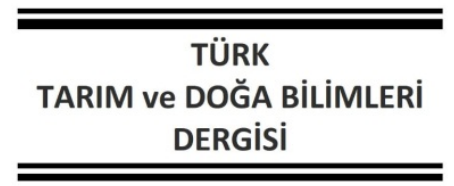

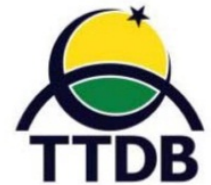

www.dergipark.gov.tr/turkjans

Araştırma Makalesi

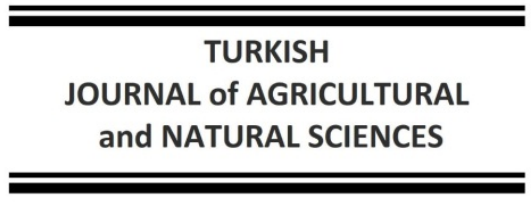

ORNAL OF AGR

\title{
Mutasyon Islahı İle Geliştirilmiş Bazı Aspir (Carthamus tinctorius L.) Hatlarının Tarımsal Performansları
}

\author{
Arzu KÖSE ${ }^{1 *}$, Ferda ÇELIKOĞLU KOŞAR ${ }^{1}$, Özlem BILIR² \\ ${ }^{1}$ Geçit Kuşağı Tarımsal Araştırma Enstitüsü, Eskişehir \\ ${ }^{2}$ Trakya Tarımsal Araştırma Enstitüsü, Edirne \\ *Sorumlu Yazar: arzukose.tr@gmail.com
}

\section{Geliş Tarihi: 07.02.2020 Düzeltme Geliş Tarihi: 05.03.2021 Kabul Tarihi: 06.04.2021}

\section{$\overline{O ̈ z}$}

Bu çalışma, Eskişehir ekolojik koşulları altında, bazı aspir hat ve çeşitlerine ait tane ve yağ verimleri ile verim komponentlerinin belirlenmesi amacı ile yürütülmüştür. Araştırma, 2015, 2016 ve 2017 yıllarında, Geçit Kuşağı Tarımsal Araştırma Enstitüsü (GKTAE) deneme tarlalarında gerçekleştirilmiştir. Çalışmada, GKTAEEskişehir tarafından geliştirilmiş 12 adet hat ve 3 standart çeşit (Dinçer, Balcı, Linas) kullanılmıştır. Çalışmada kullanılan hatlar mutasyon ıslahı yöntemi ile elde edilmiştir. Araştırma yıllarına ait veriler, tesadüf blokları deneme desenine uygun olarak analiz edilmiştir. Çalışmada, Balcı ve Linas çeşitlerinin diğer hat ve çeşitlere oranla daha yüksek yağ oranı değerine sahip oldukları, birim alan tane ve yağ verimi bakımından ES-MUT-1 hattının ön plana çıktığı tespit edilmiştir.

Anahtar kelimeler: Aspir, mutasyon, hat, tane verimi, yağ verimi

\section{Agricultural Performances of Some Safflower (Carthamus tinctorius L.) Lines Developed By Mutation Breeding Method}

\begin{abstract}
This study was carried out to determine seed and oil yield with their components of some safflower lines and varieties under Eskisehir ecological conditions. This research was conducted at the experimental fields of Transitional Zone Agricultural Research Institute (TZARI), during 2015, 2016 and 2017. Both twelve safflower lines and three varieties (Dincer, Balci, Linas) originating from TZARI-Eskisehir were evaluated in this research. The lines used in this study are developed by using mutation breeding method. Data for research years were collected and analyzed according to randomized block design with three replications. In the study Balci and Linas varieties have higher oil content than other lines and varieties, especially it was determined to ES-MUT-1 has the highest variety in terms of seed and oil yield.
\end{abstract}

Key words: Safflower, mutation, line, seed yield, oil yield

\section{Giriş}

Aspir, (Carthamus tinctorious L.) farklı kullanım alanlarına sahip, yalancı safran ve/veya Amerikan safranı gibi isimlerle bilinen tek yıllık bir bitkidir. Günümüzde tanelerinin içerdiği yüksek kalitede yağ nedeni ile genellikle yağ bitkisi olarak kullanılmaktadır. Uzun yıllardan beri ülkemizde tarımı yapılan bu bitki, kurağa dayanımı nedeni ile genellikle kurak ve yarı kurak alanlarda yayılış göstermiştir.

Ülkemiz bitkisel yağ açığı nedeni ile hemen hemen her yıl 2.5 - 3 milyar dolar civarında döviz kaybına uğramaktadır (Anonim, 2019). Bu açı̆̆ı gidermede yağlı tohumlu bitkilerin üretimini arttırmak bir zorunluluktur. Türkiye'de üretimi yapılan yağlı tohumlu bitkilerin ekolojik sınırına 
gelinmiş olması, bitkisel yağ açığını gidermede sınırlayıcı bir faktördür. Bu nedenle, ürün deseni bağlı olduğu, ortalama yağışı 300-350 mm civarında olan bölgelerde genellikle buğday-nadas ekim sistemi uygulanmaktadır. Bu bölgelerde aspir dışındaki diğer yağlı tohumlu bitkilerin yetiştiriciliğinin yapılmasında su sınırlayıcı faktör olmaktadır. Aspir, kök sisteminin etkisi nedeni ile topraktaki besin maddesi ve sudan çok iyi faydalanmakta olup, bu durum bitkinin kurağa mukavemetini arttırmaktadır. Bu özelliği nedeni ile Orta Anadolu ve benzer ekolojilere sahip bölgeler, bitkinin en uygun yetişme imkânı bulabileceği alanlardır. Geniş adaptasyon yeteneğine sahip farklı ekolojilerde yetişebilen aspir bitkisi, kışları ılıman geçen bölgelerde kışlık olarak rahatlıkla yetiştirilebilmektedir. Ancak, Orta Anadolu ve benzer ekolojilerde bitki kıştan zarar gördüğü için üretimi yazlık olarak yapılmaktadır. Türkiye'de yaklaşık 3.5 milyon hektar nadas alanı mevcut olup bu alanların \% 65'lik kısmı Orta Anadolu bölgesinde yer almaktadır (Anonim, 2018). Bu alanlarda devam içerisine farklı yağlı tohumlu bitkilerin girmesi gerekmektedir. Ülkemizde bitkisel üretimin yağışa eden buğday-nadas ekim sistemi yerine buğdayaspir-nadas ekim sisteminin devreye sokulması aspir ekim alanlarını arttırabilecektir.

Aspir ıslah araştırmalarının temel hedefi üretici, tüketici ve sanayici isteklerine uygun yeni aspir genotiplerini geliştirerek bunları üretim zincirine sokmaktır. Bu hedefi gerçekleştirmede genetik varyasyonu sağlamak amacı ile farklı ıslah yöntemleri kullanılmakta olup, mutasyon ıslahı da bu amaçla kullanılan yöntemlerden biridir (Ekingen, 1991; Demirsoy, 1997; Patil ve ark., 2001; Parameshwarappa ve Meghannavar, 2001). Bu yöntemde, değişik ışın kaynaklarını mutagen olarak kullanarak varyasyon yaratma hedeflenmektedir (Anonim, 2004).

Bu çalışmada; mutasyon ıslahı yöntemi ile geliştirilmiş aspir genotipleri arasındaki verim ve verim unsurları bakımından farklılıkları ortaya koymak, özellikle tane ve yağ verimi bakımından üstün genotipleri belirlemek amaçlanmıştır.

Çizelge 1. Deneme yıllarına (2015-2017) ve uzun yıllar (1965-2014) ortalamasına ait iklim verileri

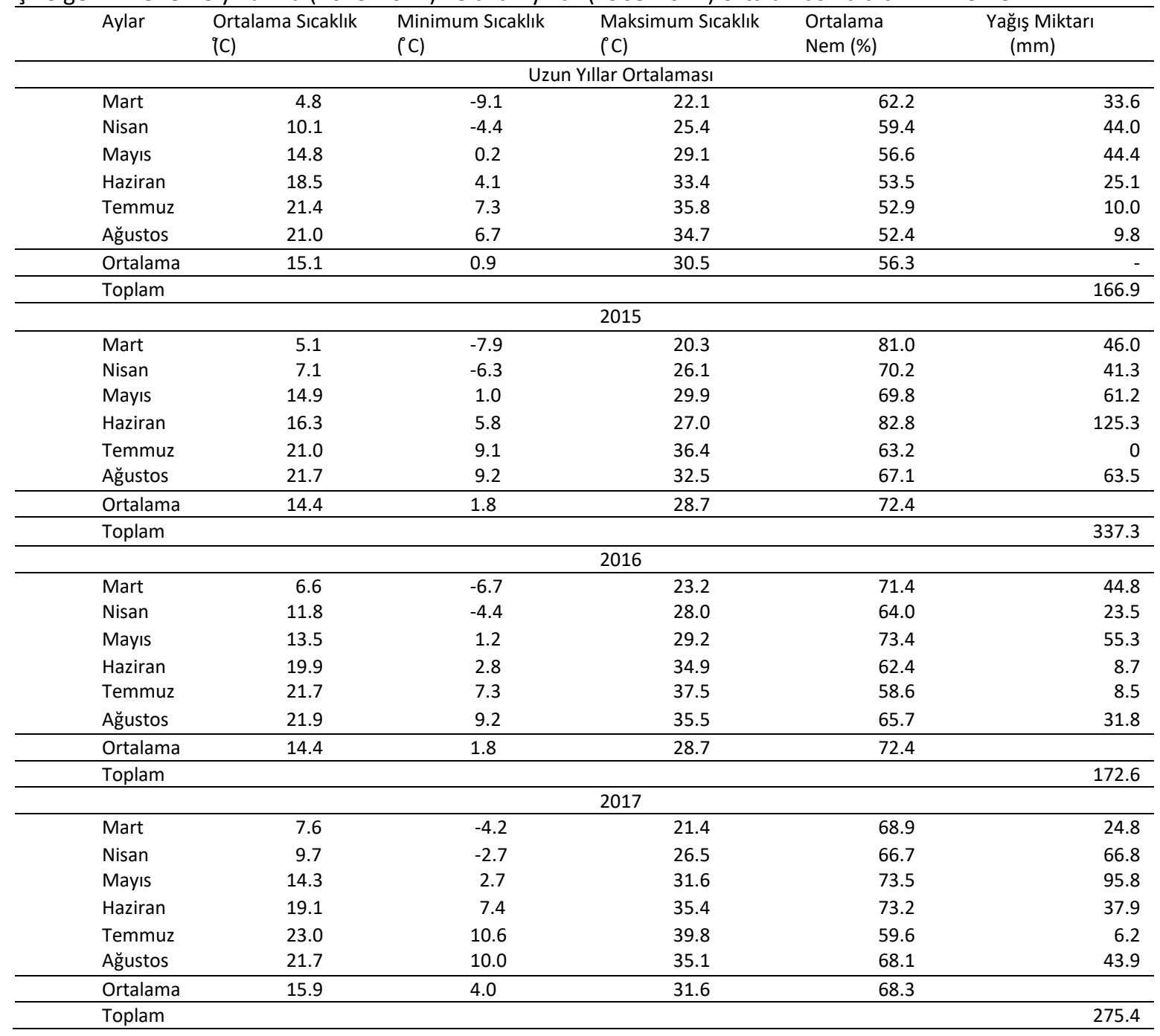




\section{Materyal ve Metot}

Çalışma, Eskişehir Geçit Kuşağı Tarımsal Araştırma Enstitüsü araştırma alanında kıraç koşullarda yürütülmüştür. Deneme yeri özellikle yazların sıcak ve kurak, kışların ise soğuk ve sert olduğu bir karasal iklim olan geçit kuşağı iklim tipine sahiptir. Deneme yerinin 2015, 2016, 2017 ve uzun yıllar ortalamasına ait (1965-2014) iklim değerleri Çizelge 1'de verilmiştir. Araştırma alanı toprağı hafif alkali ve kumlu-killi bir yapıya sahip olup, organik maddece fakir (\%1.1)'dir.

Araştırmada, 15 adet mutant hat ve 3 adet aspir çeşidi standart olarak kullanılmıştır (Çizelge 2). Aspir mutant hatları ile ilgili çalışmaya 2007 yılında başlanmış olup 5 adet aspir hattına 100, 200 ve 400 gray'lik dozlar uygulamaları gerçekleştirilmiştir. Doz uygulamasının gerçekleştirildiği hatlar; geçci özellikte olup, dikenli, sarı çiçek yapısına sahip, genel olarak yağ oranları \%28-32 arasında değişim gösteren genotiplerden seçilmiştir. Kullanılacak uygun dozların belirlenmesinde aspir bitkisi ile yapılan önceki çalışmalardan yararlanılmıştır (Uslu 1997). Çalışmada, $M_{2}$ generasyonundan çok sayıda bitki seçilip bunlar $\mathrm{M}_{3}$ hatları olarak ayrı ayrı yetiştirilmiştir (Khadeer ve Anwar, 1990; Mozaffari ve Asadi, 2006). Çalışmaya $M_{8}$ generasyonuna kadar genetik açılmaların takibi ve seleksiyon işlemleri ile devam edilmiş olup, seçilen hatlar 2015-2017 yılları arasında verim denemelerine alınmıştır. Denemeler tesadüf blokları deneme desenine göre 3 tekerrür halinde, $5 \mathrm{~m}$ uzunluğundaki parsellere, her parselde 6 sıra, sıra arası $45 \mathrm{~cm}$, ekim normu $4 \mathrm{~kg} /$ da olacak şekilde ekilmiştir (Turan, 1995). Çalışmada, gübre olarak ekim ile birlikte $8 \mathrm{~kg} / \mathrm{da} \mathrm{N}$ ve $6 \mathrm{~kg} / \mathrm{da} \mathrm{P}_{2} \mathrm{O}_{5}$ kullanılmıştır. Denemelerin ekimi her üç yılda da mart ayının ikinci haftasında gerçekleştirilmiştir. Deneme süresince yabancı ot kontrolü elle gerçekleştirilmiş olup hasat, deneme yıllarında Ağustos ayının ikinci haftasında yapılmıştır.

Denemede; çiçeklenme gün sayısı, bitki boyu, bitkide tabla sayısı, tabla çapı, 1000 tane ağırlığı, yağ oranı, tohum verimi ve yağ verimi değerleri incelenmiştir. Her parsele ait yağ oranları Soxhlet cihazında hegzanla 4 saat boyunca muamele edilerek belirlenmiştir. Yağ verimi değerleri her parsele ait tohum verimi ve yağ oranı ile çarpılarak elde edilmiştir. Sonuçlar SAS istatistik paket programı kullanılarak analiz edilmiş ve ortalamalar A.Ö.F. (\% 5) testi ile değerlendirilmiştir.

Çizelge 2. Genotiplere ait pedigreler ve kodları

\begin{tabular}{cll}
\hline Hat ve Çeşit no & \multicolumn{1}{c}{ Pedigre } & \multicolumn{1}{c}{ Kod } \\
\hline 1 & AÇ1D1.15.4.1.1 & ES-MUT-1 \\
3 & AÇ1D1.27.2.1 & ES-MUT-2 \\
4 & AÇ1D1.30.1.2.1 & ES-MUT-3 \\
5 & Aç1D1.30.3.3.1 & ES-MUT-4 \\
6 & AÇ1D1.34.2.1 & ES-MUT-5 \\
7 & Aç1D1.36.4.4.1 & ES-MUT-6 \\
8 & AÇ2D1.2.1.3.1 & ES-MUT-7 \\
9 & AÇ3D1.0.4.1.1 & ES-MUT-8 \\
10 & AÇ4D1.20.1.1 & ES-MUT-9 \\
11 & AÇ5D1.7.4.2.1 & ES-MUT-10 \\
12 & Aç3D3.3.2.2.1 & ES-MUT-11 \\
13 & AÇ4D3.2.2.1 & ES-MUT-12 \\
14 & Standart Çeşit-1 & DiNÇER \\
15 & Standart Çeşit-2 & BALCI \\
\hline
\end{tabular}

\section{Bulgular ve Tartışma}

2015-2017 yıllarında yürütülen bu çalışmada ele alınan özellikler Bartlett ve Kendall (1946) homojenlik testine tabi tutulmuştur. Yıllara ait varyansların bitkide tabla sayısı özelliği dışında incelenen tüm karakterlerde eşit olması nedeni ile üç yıla ait değerler birleştirilerek analiz edilmiştir. Bu çalışmada kullanılan aspir (Carthamus tinctorius L.). genotiplerine ait incelenen karakter bakımından gerçekleştirilen varyans analizi sonuçları Çizelge 3'de yer almaktadır. 
Çizelge 3. Incelenen karakterlere ait varyans analiz tablosu

$$
\text { Kareler Ortalaması }
$$

\begin{tabular}{|c|c|c|c|c|c|c|c|c|c|}
\hline V.K & SD & $\begin{array}{c}\text { Çiçeklenme } \\
\text { Gün } \\
\text { Sayısı }\end{array}$ & $\begin{array}{l}\text { Bitki } \\
\text { Boyu }\end{array}$ & $\begin{array}{l}\text { Tabla } \\
\text { Sayısı }\end{array}$ & $\begin{array}{l}\text { Tabla } \\
\text { Çapı }\end{array}$ & $\begin{array}{l}1000 \\
\text { Tane } \\
\text { Ağırlığı }\end{array}$ & $\begin{array}{c}\text { Tane } \\
\text { Verimi }\end{array}$ & $\begin{array}{l}\text { Yağ } \\
\text { Oranı }\end{array}$ & $\begin{array}{c}\text { Yağ } \\
\text { Verimi }\end{array}$ \\
\hline$Y$ & 2 & $2525.96^{*}$ & 9011.17* & $42.15^{\text {öd }}$ & $0.527^{*}$ & 5.19öd & $20246.6 * *$ & $125.59 * *$ & $3307.3^{* *}$ \\
\hline G & 14 & $6.9365^{* *}$ & $78.57^{*}$ & $2.85^{*}$ & $0.089 * *$ & $66.33 * *$ & $4432.4 * *$ & $60.04 * *$ & $643.0 * *$ \\
\hline$Y \times G$ & 28 & $2.36825^{* *}$ & $30.25^{\text {öd }}$ & $1.65^{o ̈ d}$ & $0.022^{\text {öd }}$ & $13.58^{* *}$ & $1982.6 * *$ & $9.55^{*}$ & $257.9 * *$ \\
\hline Hata & 84 & 1.708 & 27.60 & 1.06 & 0.017 & 6.35 & 325.22 & 4.44 & 44.1 \\
\hline D.K. (\%) & & 1.6 & 5.76 & 11.76 & 6.89 & 7.90 & 14.02 & 6.42 & 15.6 \\
\hline
\end{tabular}

*,*: İstatistiki olarak sırasıyla \%5, \%1 düzeyinde önemli, öd: önemli değil

Denemede incelenen çiçeklenme gün sayısı, bitki boyu, tabla çapı, tane verimi, yağ oranı ve yağ verimi bakımından yıllar arasında istatistiki olarak fark belirlenmiş olup, genotipler arası fark, incelenen tüm karakterler bakımından istatistiki olarak önemlidir. Bununla birlikte, yıl $\times$ genotip interaksiyonu bakımından bitki boyu, bitkide tabla sayısı, tabla çapı dışındaki karakterlerde istatistiki fark belirlenmiştir.

Gerek ıslah çalışmalarında gerekse bitkisel üretimde temel hedef verimi artırmak olup bu karakter fazla sayıda faktörün etkisi altındadır. Bu açıdan incelendiğinde üzerinde çalışılan genotiplerin sadece verim değerleri dikkate alınarak yapılan değerlendirmelerin yeterli olmadığı, verime etki eden diğer faktörlerin de irdelenmesi gerektiği bildirilmektedir (Omidi ve ark., 2012).

Çiçeklenme gün sayısı bakımından yıllara göre ortalama değer 2015 yılında 75.6 gün, 2016 yılında 75.1 gün, 2017 yılında ise 74.0 gün olarak belirlenmiştir (Çizelge 4).

Çizelge 4. Çiçeklenme gün sayısı bakımından yıllara ve genotiplere ait ortalama değerler

\begin{tabular}{|c|c|c|c|c|c|c|c|c|}
\hline \multicolumn{9}{|c|}{ Çiçeklenme Gün Sayısı (gün) } \\
\hline Hatlar ve Çeşitler & 2015 & & 2016 & & 2017 & & Ort & \\
\hline ES-MUT-1 & 77.3 & jl & 74.3 & $f i$ & 73.5 & ce & 75.0 & $\mathrm{~cd}$ \\
\hline ES-MUT-2 & 75.0 & $m n$ & 74.7 & $g j$ & 72.8 & ce & 74.2 & $d$ \\
\hline ES-MUT-3 & 75.3 & $\ln$ & 75.3 & $f g$ & 74.5 & $b d$ & 75.0 & $\mathrm{~cd}$ \\
\hline ES-MUT-4 & 75.0 & $m n$ & 75.0 & fh & 73.8 & $c d$ & 74.6 & $\mathrm{~cd}$ \\
\hline ES-MUT-5 & 75.7 & $\ln$ & 77.3 & fh & 73.8 & $a b$ & 75.6 & bc \\
\hline ES-MUT-6 & 74.7 & $m n$ & 75.0 & fh & 73.8 & $c d$ & 74.5 & $\mathrm{~cd}$ \\
\hline ES-MUT-7 & 74.3 & $n$ & 74.0 & $f g$ & 74.5 & de & 74.3 & $d$ \\
\hline ES-MUT-8 & 74.7 & $m n$ & 75.0 & fh & 73.8 & $c d$ & 74.5 & $\mathrm{~cd}$ \\
\hline ES-MUT-9 & 74.7 & $m n$ & 76.0 & fh & 74.2 & $a d$ & 75.0 & $\mathrm{~cd}$ \\
\hline ES-MUT-10 & 75.0 & $m n$ & 74.7 & $g ı$ & 73.2 & ce & 74.3 & $d$ \\
\hline ES-MUT-11 & 75.3 & $m n$ & 76.0 & fh & 73.8 & $a d$ & 75.0 & $\mathrm{~cd}$ \\
\hline ES-MUT-12 & 74.7 & $m n$ & 75.0 & $f g$ & 74.5 & $c d$ & 74.7 & $\mathrm{~cd}$ \\
\hline DINÇER & 77.3 & jl & 76.3 & $f$ & 75.5 & $a c$ & 76.4 & $a b$ \\
\hline BALCI & 76.7 & $\mathrm{~km}$ & 72.7 & $h k$ & 72.2 & $e$ & 73.9 & $d$ \\
\hline LINAS & 78.0 & ık & 75.1 & $f$ & 75.5 & $a$ & 76.2 & $\mathrm{a}$ \\
\hline Ort & 75.6 & A & 75.1 & A & 74.0 & B & 74.9 & \\
\hline
\end{tabular}

Deneme yıllarında çiçeklenme periyodunu içine alan temmuz ayında yağışların uzun yıllar ortalamasının altında, maksimum sıcaklık değerlerinin ise üstünde olması bitkilerin daha kısa sürede çiçeklenmesine sebep olmuştur. Özellikle 2017 yılında yaşanan kuraklık bu çalışma yılında bitkilerin daha erken çiçeklenmelerine sebep olmuştur. Alizadeh (2005), farklı orjinli hatlar ile yürüttüğü araştırmada, çiçeklenme gün sayısının 102-124 gün arasında değiştiğini belirlemiştir. Alizadeh (2005)' in çalışmaları ile bizim araştırmamızın sonuçları arasında görülen 
farklılıklar çevresel faktörlerle beraber genetik yapıların farkından da kaynaklanmaktadır. Denemede en uzun çiçeklenme süresi 2017 yılında ES-MUT-13, en kısa çiçeklenme süresi ise 2015 yılında ES-MUT-7 nolu hatlardan elde edilmiştir. Yıllara ait ortalama değerler dikkate alındığında en geçci genotipin Linas çeşidi olduğu belirlenmiştir.

Çalışmanın ilk yılında, aspir hat ve çeşitlerine ait ortalama bitki boyu değeri $97.7 \mathrm{~cm}$, ikinci yılında ise $83.4 \mathrm{~cm}$, üçüncü yılında ise $82.9 \mathrm{~cm}$ olarak bulunmuştur. 2015 yılında bitkinin sapa kalkma döneminde ve çiçeklenme öncesi dönemlerde alınan yüksek yağış ve bu aylarda diğer deneme yıllarına göre daha düşük sıcaklık değerleri, bitkilerin boy uzamasını teşvik etmiştir. Yıllara ait ortalama değerler dikkate alındığında en yüksek bitki boyu değerinin $93.3 \mathrm{~cm}$ ile Linas, en düşük değerin ise $81.6 \mathrm{~cm}$ ile ES-MUT-6 nolu hattında belirlenmiştir (Çizelge 5).

Çizelge 5. Bitki boyu bakımından yıllara ve genotiplere ait ortalama değerler

\begin{tabular}{|c|c|c|c|c|c|}
\hline \multicolumn{6}{|c|}{ Bitki Boyu $(\mathrm{cm})$} \\
\hline Hatlar ve Çeşitler & 2015 & 2016 & 2017 & Ort & \\
\hline ES-MUT-1 & 95.5 & 82.0 & 85.2 & 87.6 & bc \\
\hline ES-MUT-2 & 97.5 & 85.0 & 83.5 & 88.7 & $a b$ \\
\hline ES-MUT-3 & 95.5 & 87.5 & 86.3 & 89.8 & $a b$ \\
\hline ES-MUT-4 & 96.0 & 89.0 & 78.7 & 87.9 & $b$ \\
\hline ES-MUT-5 & 93.0 & 86.5 & 82.3 & 87.3 & bc \\
\hline ES-MUT-6 & 95.0 & 76.5 & 73.2 & 81.6 & d \\
\hline ES-MUT-7 & 100.5 & 84.0 & 79.0 & 87.8 & $b$ \\
\hline ES-MUT-8 & 98.5 & 79.0 & 81.8 & 86.4 & bd \\
\hline ES-MUT-9 & 102.0 & 80.0 & 86.5 & 89.5 & $a b$ \\
\hline ES-MUT-10 & 100.0 & 81.0 & 84.3 & 88.4 & $a b$ \\
\hline ES-MUT-11 & 96.5 & 83.0 & 83.8 & 87.8 & $b$ \\
\hline ES-MUT-12 & 102.5 & 85.5 & 85.8 & 91.3 & $a b$ \\
\hline DINÇER & 101.5 & 83.5 & 84.8 & 89.9 & $a b$ \\
\hline BALCl & 93.0 & 78.0 & 77.0 & 82.7 & $\mathrm{~cd}$ \\
\hline LINAS & 98.0 & 91.0 & 91.0 & 93.3 & a \\
\hline Ort & $97.7 \mathrm{~A}$ & $83.4 \mathrm{~B}$ & $82.9 \mathrm{~B}$ & 87.6 & \\
\hline
\end{tabular}

Çalışmada kullanılan hatların genel olarak orta boylu olduğu ve aşırı boylanmadığı tespit edilmiştir. Aspir bitkisinde aşırı boylanma bitkilerin topraktan fazla miktarda su ve besin maddesi kaldırmasına sebep olmaktadır. Weiss (2000) aspir yetiştiriciliğinde en uygun bitki boyu yüksekliğinin 60-80 cm arasında değişmesi gerektiğini vurgulamaktadır. Çamaş ve Esendal (2006), 5 farklı bölgede yürüttükleri çalışmada bitki boyunun 66$139 \mathrm{~cm}$ arasında değiştiğini ve bu özellik üzerine çevre şartlarının etkisinin daha az olduğunu rapor etmişlerdir.

Araştırmada, bitkide tabla sayısı bakımından genotiplere ait ortalama değerler dikkate alındığında; en yüksek değer 11.7 adet ile ES-MUT-
3 nolu genotipten en düşük değer ise 9.2 adet ile ESMUT-9 nolu genotipten elde edildiği belirlenmiştir (Çizelge 6). Aspir ıslah çalışmalarında tohum verimini etkileyen seleksiyon kriterlerinin başında bitkide tabla sayısı gelmektedir (Köse ve ark., 2018). Aspir bitkisi ile çalışan diğer araştırıcılar en yüksek tabla sayısını sırası ile 9.9 adet; 30 adet; 20 adet 19.5 adet ve 23.7 adet olarak belirlemişlerdir (Bayraktar, 1995; Cazzato ve ark., 2001; Tonguç ve Erbaş, 2009, Beyyavaş ve ark., 2011 ve Ada, 2013). Araştırma sonuçlarımız ile farklılık gösteren bu değerler başta genotipik ve çevresel faktörlerin farklılığından kaynaklanabilir. Arslan (2007), yürüttüğü çalışmada tabla sayısı özelliğinin diğer özelliklere göre çevre koşullarından daha fazla etkilendiğini rapor etmiştir. 
Çizelge 6. Bitkide tabla sayısı bakımından yıllara ve genotiplere ait ortalama değerler

\begin{tabular}{|c|c|c|c|c|c|}
\hline \multicolumn{6}{|c|}{ Bitkide Tabla Sayısı (adet) } \\
\hline Hatlar ve Çeşitler & 2015 & 2016 & 2017 & Ort & \\
\hline ES-MUT-1 & 10.2 & 10.8 & 12.4 & 11.1 & $a b$ \\
\hline ES-MUT-2 & 9.6 & 10.6 & 10.7 & 10.3 & bc \\
\hline ES-MUT-3 & 10.4 & 10.0 & 14.8 & 11.7 & $\mathrm{a}$ \\
\hline ES-MUT-4 & 9.7 & 10.9 & 11.3 & 10.6 & bc \\
\hline ES-MUT-5 & 9.6 & 10.0 & 10.8 & 10.1 & C \\
\hline ES-MUT-6 & 9.4 & 9.3 & 11.4 & 10.0 & $\mathrm{~cd}$ \\
\hline ES-MUT-7 & 9.4 & 10.3 & 11.4 & 10.4 & bc \\
\hline ES-MUT-8 & 9.2 & 10.1 & 11.7 & 10.4 & bc \\
\hline ES-MUT-9 & 9.4 & 8.3 & 9.9 & 9.2 & $d$ \\
\hline ES-MUT-10 & 9.5 & 10.3 & 12.7 & 10.8 & ac \\
\hline ES-MUT-11 & 9.3 & 10.6 & 10.5 & 10.1 & $\mathrm{~cd}$ \\
\hline ES-MUT-12 & 9.1 & 10.7 & 11.6 & 10.5 & bc \\
\hline DINÇER & 9.6 & 10.1 & 11.4 & 10.4 & bc \\
\hline $\mathrm{BALCl}$ & 10.5 & 10.0 & 10.5 & 10.3 & bc \\
\hline LINAS & 9.9 & 9.0 & 11.4 & 10.1 & $\mathrm{~cd}$ \\
\hline Ort. & 9.7 & 10.1 & 11.5 & 10.4 & \\
\hline
\end{tabular}

Bu çalışmada, ortalama tabla çapı değeri $2015 \mathrm{~cm}$ yılında $1.84 \mathrm{~cm}, 2016$ yılında $1.91 \mathrm{~cm} 2017$ yılında ise $2.05 \mathrm{~cm}$ olarak belirlenmiştir. Bu özellik bakımından yıllara ait ortalama değerler dikkate alındığında en yüksek tabla çapı değerinin $2.08 \mathrm{~cm}$ ile ES-MUT- 1 hattından en düşük değerin ise 1.73 cm ile ES-MUT- 4 hattında alındığı görülmektedir (Çizelge 7).

Çamaş ve Esendal (2006), yürüttükleri çalışmada tabla çapı değerinin $1.5-2.1 \mathrm{~cm}$ arasında değiştiğini ve bu özellik üzerine çevre şartlarının etkisinin fazla olduğunu vurgulamaktadır.

Çizelge 7. Tabla çapı bakımından yıllara ve genotiplere ait ortalama değerler.

\begin{tabular}{|c|c|c|c|c|c|}
\hline \multirow[b]{2}{*}{ Hatlar ve Çeşitler } & \multicolumn{5}{|c|}{ Tabla Çapı (cm) } \\
\hline & 2015 & 2016 & 2017 & Ort. & \\
\hline ES-MUT-1 & 1.93 & 2.10 & 2.22 & 2.08 & $\mathrm{a}$ \\
\hline ES-MUT-2 & 1.88 & 1.98 & 2.17 & 2.01 & $\mathrm{ad}$ \\
\hline ES-MUT-3 & 1.87 & 1.93 & 2.17 & 1.99 & ae \\
\hline ES-MUT-4 & 1.52 & 1.86 & 1.82 & 1.73 & $\mathrm{~h}$ \\
\hline ES-MUT-5 & 1.68 & 1.87 & 2.11 & 1.89 & $\mathrm{dg}$ \\
\hline ES-MUT-6 & 1.85 & 1.82 & 1.97 & 1.88 & eg \\
\hline ES-MUT-7 & 1.72 & 1.79 & 2.07 & 1.86 & $\mathrm{fg}$ \\
\hline ES-MUT-8 & 1.92 & 1.88 & 2.01 & 1.93 & bg \\
\hline ES-MUT-9 & 1.93 & 2.00 & 2.12 & 2.02 & ac \\
\hline ES-MUT-10 & 1.98 & 1.83 & 2.11 & 1.97 & af \\
\hline ES-MUT-11 & 1.78 & 1.76 & 1.92 & 1.82 & gh \\
\hline ES-MUT-12 & 1.73 & 1.73 & 1.98 & 1.81 & gh \\
\hline DINÇER & 1.78 & 1.87 & 2.07 & 1.91 & $\mathrm{cg}$ \\
\hline $\mathrm{BALCl}$ & 1.97 & 2.09 & 1.94 & 2.00 & ae \\
\hline LINAS & 2.02 & 2.08 & 2.07 & 2.06 & $a b$ \\
\hline Ort. & $1.84 \mathrm{~B}$ & $1.91 \mathrm{~B}$ & $2.05 \mathrm{~A}$ & 1.92 & \\
\hline
\end{tabular}

Araştırmada, yıllara ait ortalama değerler dikkate alındığında, 1000 tane ağırlığının 31.7 - 40.4 gr arasında değiştiği belirlenmiştir. Ayrıca, denemenin birinci yılında ES-MUT- 6 (46.9 g) genotipi, ikinci yılında Balcı (48.8 g) üçüncü yılında ise ES-MUT- 3 hattı (40.7 g) en yüksek 1000 tane ağırlığı değerine sahip olmuşlardır (Çizelge 8). Bu sonuçlar, aspir genotiplerinin 1000 tane ağırlığı bakımından yıllara bağlı olarak değişen iklim ve çevre faktörlerinden etkilendiğinin bir göstergesidir. Alizadeh (2005), Camaş ve Esendal (2006) ve Tonguç ve Erbaş (2009) farklı aspir genotipleri ile farklı 
ekolojilerde yürüttükleri çalışmalarında yüksek 1000 tane ağırlığı değerini sırası ile 54.0 g, 48.0 g ve 49.1 olarak belirlemişlerdir.
Araştırmanın yürütüldüğü 2015, 2016 ve 2017 yıllarında denemeye ait ortalama verim değerleri sırası ile $104.7 \mathrm{~kg} / \mathrm{da}, 135.5 \mathrm{~kg} /$ da ve 145.4 kg/da'dır (Çizelge 9).

Çizelge 8. 1000 tane ağırlığı bakımından yıllara ve genotiplere ait ortalama değerler

\begin{tabular}{|c|c|c|c|c|c|c|c|c|}
\hline \multicolumn{9}{|c|}{1000 Tane Ağırlığı (g) } \\
\hline Hatlar ve Çeşitler & 2015 & & 2016 & & 2017 & & Ort. & \\
\hline ES-MUT-1 & 39.6 & $b d$ & 37.0 & $\mathrm{Cl}$ & 37.6 & $b ı$ & 38.2 & $\mathrm{ac}$ \\
\hline ES-MUT-2 & 33.6 & וp & 35.4 & en & 34.5 & ho & 34.4 & de \\
\hline ES-MUT-3 & 38.5 & $b h$ & 38.7 & $b f$ & 40.7 & $b c$ & 38.5 & $a b$ \\
\hline ES-MUT-4 & 29.9 & $p q$ & 31.1 & $o q$ & 31.5 & $m q$ & 34.8 & $f$ \\
\hline ES-MUT-5 & 35.4 & en & 36.6 & $d ı$ & 35.6 & $d m$ & 35.8 & $\mathrm{~cd}$ \\
\hline ES-MUT-6 & 46.9 & $a$ & 35.7 & $d l$ & 38.6 & $b g$ & 40.4 & a \\
\hline ES-MUT-7 & 35.8 & $d l$ & 35.6 & $d l$ & 35.8 & $d l$ & 36.1 & $\mathrm{~cd}$ \\
\hline ES-MUT-8 & 41.5 & $b$ & 33.8 & ip & 37.6 & $b ı$ & 35.6 & bc \\
\hline ES-MUT-9 & 34.7 & fo & 34.3 & 10 & 34.6 & go & 34.9 & de \\
\hline ES-MUT-10 & 29.4 & $q$ & 31.8 & $l q$ & 31.4 & $n q$ & 34.2 & $f$ \\
\hline ES-MUT-11 & 34.6 & go & 35.8 & $d l$ & 35.2 & en & 31.7 & g \\
\hline ES-MUT-12 & 34.0 & וp & 36.2 & $d k$ & 34.4 & ho & 36.6 & de \\
\hline DINÇER & 34.1 & 10 & 32.2 & $k q$ & 32.5 & $j q$ & 35.6 & ef \\
\hline $\mathrm{BALCl}$ & 33.7 & ip & 38.8 & be & 36.7 & $\mathrm{Cl}$ & 32.1 & $\mathrm{~g}$ \\
\hline LINAS & 36.5 & $d j$ & 34.9 & eo & 36.2 & $d k$ & 35.3 & $\mathrm{~cd}$ \\
\hline Ort. & 35.9 & & 35.2 & & 35.5 & & 35.7 & \\
\hline
\end{tabular}

Çizelge 9. Tane verimi bakımından yıllara ve genotiplere ait ortalama değerler.

\begin{tabular}{|c|c|c|c|c|c|c|c|c|}
\hline \multicolumn{9}{|c|}{ Tane Verimi (kg/da) } \\
\hline Hatlar ve Çeşitler & 2015 & & 2016 & & 2017 & & Ort. & \\
\hline ES-MUT-1 & 187.0 & $a b$ & 169.4 & $a e$ & 172.2 & ad & 179.5 & a \\
\hline ES-MUT-2 & 101.3 & 19 & 134.3 & $g k$ & 137.7 & $f k$ & 119.5 & $\mathrm{df}$ \\
\hline ES-MUT-3 & 123.0 & $\mathrm{Im}$ & 147.5 & $\mathrm{dj}$ & 189.3 & a & 156.1 & $b$ \\
\hline ES-MUT-4 & 99.7 & 19 & 112.5 & ko & 122.2 & $1 q$ & 110.9 & $f$ \\
\hline ES-MUT-5 & 90.8 & $n q$ & 154.6 & $c h$ & 151.6 & $d ı$ & 121.1 & ce \\
\hline ES-MUT-6 & 140.3 & $e k$ & 120.2 & jm & 182.7 & $a c$ & 161.5 & bc \\
\hline ES-MUT-7 & 90.0 & $n q$ & 160.4 & $a g$ & 78.9 & $p r$ & 84.4 & $\mathrm{fg}$ \\
\hline ES-MUT-8 & 128.2 & $h l$ & 166.4 & $a f$ & 125.8 & $h l$ & 126.9 & bd \\
\hline ES-MUT-9 & 59.7 & $r$ & 136.1 & $g k$ & 159.8 & $b f$ & 109.7 & ef \\
\hline ES-MUT-10 & 80.0 & $p r$ & 100.3 & $1 q$ & 94.8 & $m q$ & 87.4 & $\mathrm{~h}$ \\
\hline ES-MUT-11 & 102.8 & Ip & 119.1 & jn & 181.1 & $a c$ & 141.9 & ce \\
\hline ES-MUT-12 & 78.0 & $p r$ & 112.7 & ko & 88.8 & $p r$ & 83.4 & gh \\
\hline DINÇER & 72.7 & $q r$ & 138.1 & $f k$ & 186.0 & $a b$ & 129.3 & ce \\
\hline $\mathrm{BALCl}$ & 101.4 & 19 & 146.5 & $d j$ & 162.7 & $a g$ & 132.0 & bd \\
\hline LINAS & 116.0 & ko & 114.0 & ko & 147.5 & $d j$ & 131.7 & $d f$ \\
\hline Ort. & 104.7 & $C$ & 135.5 & B & 145.4 & $A$ & 124.6 & \\
\hline
\end{tabular}

Bu farklılık aspir genotiplerinin yıllara bağlı olarak oluşan iklim ve çevre faktörlerinden etkilendiğinin bir göstergesidir. Denemede en düşük tane verimi 2015 yılında alınmıştır. Bu yılda vejetasyon dönemine ait yağış miktarı uzun yıllar ortalamasının üzerinde gerçekleşmiştir. Ancak 2015 yılında çıkış ve sapa kalkma dönemlerinde gelen düzenli yağışa karşın çiçeklenme öncesi dönemdeki miktarı fazla ve kısa süreli yağışlar bitki verimi üzerine olumlu yansımamıştır. Bununla beraber nisan ve mayıs aylarındaki uzun yıllar ortalamasının üzerindeki maksimum sıcaklık değerleri özellikle haziran ayında yerini düşük sıcaklıklara bırakmış ve temmuz ayında hiç yağış alınamamıştır. Belirtilen iklimsel ekstrem durumlar verim üzerine olumsuz etkide bulunmuştur. Ayrıca bu durum bitki tane 
verimi üzerine yağışın miktarından çok, yağış dağılım ve süresinin etkili olduğunu göstermektedir. 2017 yıllarında yürütülen denemelerde diğer yıllara göre çeşitlerin verim düzeylerindeki artışın sebebi ise yağışların bitkinin suya en hassas olduğu sapa kalkma döneminde, mayıs ayında gerçekleşmesinden kaynaklanmaktadır. Agasimani ve ark. (1997) yürüttükleri çalışmada, aspir bitkisinin erken büyüme döneminde gelen yağış ve suyun tane verimi üzerine olumlu etkide bulunduğundan bahsetmektedir. Ancak bu yılda verim artışını kısıtlayan bir faktör olan sıcaklığın bitkilerin çiçeklenme dönemi olan temmuz ayında uzun yıllar ortalamasının oldukça üzerinde seyretmesi, verim artışını sınırlayıcı olmuştur. Yıllara ait ortalama değerler dikkate alındığında; en yüksek tane veriminin $179.5 \mathrm{~kg} / \mathrm{da}$ ile ES-MUT-1 nolu genotipten, en düşük tane verimin ise ES-MUT-12 nolu genotipten elde edildiği belirlenmiştir. Bu özellik bakımından genotip $x$ çevre interaksiyonunun önemli olması, çevresel faktörlerin genotip üzerine farklı etkide bulunduğunu göstermektedir. Nitekim ortalama değer bakımından en yüksek tane verimi 2017 yılında ES-MUT-3 nolu genotipten elde edilmesine karşın bu genotipten diğer deneme yıllarında bu özellik bakımından deneme ortalamasına yakın tane verimi değerleri almıştır. Bu durum, aspir genotiplerinin değişik çevre koşullarında farklılık gösterebileceğinin bir işaretidir.
Araştırmada, en yüksek yağ oranı \% 34.1 ile 2016, en düşük yağ oranı ise \%30.8 ile 2015 yılında belirlenmiştir (Çizelge 10). Bu özellik bakımından yıllara ait ortalama değerler incelendiğinde en yüksek yağ oranını \% 37.6 ile Balcı çeşidi almış ve bunu yine ayn istatistiki gruba giren Linas (\% 36.7) çeşidi takip etmiştir. Yağ oranı bakımından çalışmaya konu olan hatlar sadece standart çeşit olarak kullanılan Dinçer (\% 26.5) çeşidini geçmiştir. Johnson ve ark. (1999); Zhang ve Chen (2005); Koutroubas ve Papadoska (2005) ve Gawand ve ark. (2005) yürüttükleri çalışmalarında yağ oranlarının sırasıyla, \% 13-46, \% 23.8-40.3, \% 26.7-35.7 ve \% 26.3-28.5 arasında değişim gösterdiklerini bildirmişlerdir. Bu özellik bakımından belirlenen farklılıklar, genotip ve çevre şartları ile kültürel uygulamaların bir sonucudur. Yürütülen bu denemelerde yıllar arasında, yağ oranı bakımından farklılık belirlenmiş olsa da bu özellik açısından çeşit sıralamaları birbirine paralellik göstermiştir. $\mathrm{Bu}$ durum ise aspir bitkisinde, tanedeki yağ oranının iklim koşullarına göre değişmekle beraber ağırlıklı olarak genotipe bağlı bir karakter olduğunu göstermektedir. Hang ve Evans (1985) yürüttükleri çalışmada aspir bitkisinde yağ oranının ağırlıklı olarak çeşide bağı bir karakter olduğunu da vurgulamışlardır.

Çizelge 10. Yağ oranı bakımından yıllara ve genotiplere ait ortalama değerler.

\begin{tabular}{|c|c|c|c|c|c|c|c|c|}
\hline \multicolumn{9}{|c|}{ Yağ Oranı (\%) } \\
\hline Hatlar ve Çeşitler & 2015 & & 2016 & & 2017 & & Ort. & \\
\hline ES-MUT-1 & 33.4 & $d k$ & 34.3 & $b_{l}$ & 34.2 & $b_{l}$ & 33.8 & $\mathrm{~cd}$ \\
\hline ES-MUT-2 & 31.0 & 10 & 35.4 & $b f$ & 28.0 & $o q$ & 33.2 & eg \\
\hline ES-MUT-3 & 30.4 & jo & 32.6 & $f l$ & 32.3 & $f l$ & 31.4 & eg \\
\hline ES-MUT-4 & 32.2 & $f l$ & 32.7 & $f l$ & 31.8 & $h n$ & 32.4 & $\mathrm{df}$ \\
\hline ES-MUT-5 & 33.2 & $d l$ & 36.8 & $a c$ & 35.3 & $b g$ & 34.9 & $\mathrm{bc}$ \\
\hline ES-MUT-6 & 34.0 & bı & 36.1 & ae & 33.9 & $b ı$ & 35.0 & bc \\
\hline ES-MUT-7 & 32.1 & $\mathrm{fm}$ & 33.4 & $d k$ & 34.8 & $b h$ & 32.7 & ce \\
\hline ES-MUT-8 & 28.5 & $n q$ & 32.5 & $f l$ & 32.1 & fl & 30.5 & fh \\
\hline ES-MUT-9 & 25.2 & $q r$ & 32.9 & el & 31.9 & $g n$ & 29.0 & gl \\
\hline ES-MUT-10 & 28.7 & $m p$ & 33.7 & $c j$ & 33.0 & $d l$ & 31.2 & eg \\
\hline ES-MUT-11 & 31.8 & $g n$ & 32.6 & $f l$ & 33.1 & $d l$ & 32.2 & $d f$ \\
\hline ES-MUT-12 & 25.6 & $p r$ & 31.9 & $g n$ & 30.0 & ko & 28.7 & hı \\
\hline DINÇER & 23.3 & $r$ & 29.9 & 10 & 32.1 & $f l$ & 26.5 & I \\
\hline $\mathrm{BALCl}$ & 36.3 & $a d$ & 39.0 & $a$ & 37.1 & $a c$ & 37.6 & $\mathrm{a}$ \\
\hline LINAS & 36.3 & $a d$ & 37.2 & $a b$ & 36.2 & $a e$ & 36.7 & $a b$ \\
\hline Ort & 30.8 & $\mathrm{C}$ & 34.1 & $\mathrm{~A}$ & 33.1 & $\mathrm{~B}$ & 32.1 & \\
\hline
\end{tabular}


Genel olarak aspir ıslah araştırmalarının amacı, farklı istek gruplarına yönelik yeni aspir çeşitlerini geliştirerek bunları üretim zincirine dahil etmektir. Üretici yüksek verimli çeşitler ile üretimini gerçekleştirmek isterken, sanayici ise bu üründen maksimum düzeyde hammadde temin etmek istemektedir. Bu doğrultuda, ıslah çalışmalarında birim alan yağ verimi önemli bir unsur olarak karşımıza çıkmaktadır. Denemede yıllara göre en yüksek yağ verimi değeri, yağ oranı özelliğinde de olduğu gibi 2016 yılında 49.5 kg/da gerçekleşmiştir (Çizelge 11). Gerek tane gerekse yağ oranı özelliklerinde olduğu gibi en düşük yağ verimi 2015 yılında elde edilmiştir. Yıllara ait ortalama değerler incelendiğinde; en yüksek yağ veriminin $59.9 \mathrm{~kg} / \mathrm{da}$ ile ES-MUT-1 nolu genotipten, en düşük tane veriminin ise ES-MUT-12 (27.3 $\mathrm{kg} / \mathrm{da})$ nolu genotipten elde edildiği belirlenmiştir. YIl $x$ genotip interaksiyonunun önemli olduğu bu özellikte en yüksek ortalama değer ES-MUT-2 genotipinden 2016 yılında bulunmuştur. Kıllı ve Ermiş (2009) yürüttükleri çalışmada yağ verimini 62.5-103.1 $\mathrm{kg} / \mathrm{da}$; Tonguç ve Erbaş (2009), yağ verimini en yüksek Dinçer 5-118 çeşidinde $(37.2 \mathrm{~kg} / \mathrm{da})$, en düşük Arizona Safflower Composite III hattında (3.3 $\mathrm{kg} / \mathrm{da}$ ) bildirmişlerdir. Arslan ve Culpan (2020), yağ veriminin $33.44-55.80 \mathrm{~kg} / \mathrm{da}$ arasında değişim gösterdiğini belirlemişlerdir.

Çizelge 11. Yağ verimi bakımından yıllara ve genotiplere ait ortalama değerler.

\begin{tabular}{|c|c|c|c|c|c|c|c|c|}
\hline \multirow[b]{2}{*}{ Hatlar ve Çeşitler } & \multicolumn{8}{|c|}{ Yağ Verimi (kg/da) } \\
\hline & 2015 & & 2016 & & 2017 & & Ort. & \\
\hline ES-MUT-1 & 62.4 & $a c$ & 59.4 & $a d$ & 57.9 & $a e$ & 59.9 & a \\
\hline ES-MUT-2 & 38.4 & ip & 67.0 & $a$ & 41.3 & 10 & 48.9 & bc \\
\hline ES-MUT-3 & 30.8 & ot & 52.6 & $c h$ & 47.3 & $e k$ & 43.6 & $\mathrm{~cd}$ \\
\hline ES-MUT-4 & 32.1 & $n t$ & 40.0 & וp & 35.8 & Is & 36.0 & $\mathrm{e}$ \\
\hline ES-MUT-5 & 30.0 & pu & 56.0 & be & 54.7 & $c f$ & 46.9 & bc \\
\hline ES-MUT-6 & 47.8 & $e j$ & 66.2 & $a b$ & 40.7 & ip & 51.5 & $b$ \\
\hline ES-MUT-7 & 28.9 & $q u$ & 25.9 & $s v$ & 55.7 & be & 36.9 & $\mathrm{e}$ \\
\hline ES-MUT-8 & 36.6 & ks & 40.7 & ip & 53.5 & $c g$ & 43.6 & $\mathrm{~cd}$ \\
\hline ES-MUT-9 & 15.0 & $w$ & 52.2 & $c h$ & 43.4 & $f l$ & 36.9 & $\mathrm{e}$ \\
\hline ES-MUT-10 & 22.9 & $t v$ & 32.2 & $n t$ & 33.1 & $m t$ & 29.4 & $f$ \\
\hline ES-MUT-11 & 32.7 & $m t$ & 59.0 & $a d$ & 39.5 & ip & 43.7 & $\mathrm{~cd}$ \\
\hline ES-MUT-12 & 20.0 & uw & 28.0 & $r ı$ & 33.8 & Is & 27.3 & $f$ \\
\hline DINÇER & 16.9 & $v w$ & 55.7 & be & 44.4 & $e k$ & 39.0 & de \\
\hline BALCI & 36.8 & $j r$ & 53.8 & $c g$ & 49.8 & $d ı$ & 46.8 & bc \\
\hline LINAS & 42.2 & $h n$ & 54.2 & $c f$ & 41.4 & 10 & 45.9 & bc \\
\hline Ort & 32.9 & C & 49.5 & $A$ & 44.8 & B & 42.1 & \\
\hline
\end{tabular}

Çalışmada, ele alınan karakterler arasındaki ilişkiler değerlendirildiğinde tane verimi ile yağ verimi arasında \%1 olasılık düzeyinde pozitif yönde korelasyonun ( $r=0.512^{* *}$ ) olduğu belirlenmiştir (Çizelge 12). Benzer şekilde, Köse ve ark. (2018), çalışmalarında en yüksek korelasyon değerini tane ve yağ verimi arasında bulmuştur. Bu çalışmada, tane ve yağ verimi özellikleri bitki boyu ile negatif $\left(r=0.421^{* *}\right.$ ve $\left.r=0.466^{* *}\right)$, tabla çapı $\left(r=0.401^{* *}\right.$ ve $\left.r=0.241^{* *}\right)$ ve yağ oranı $\left(r=0.229^{* *}\right.$ ve $\left.r=0.586^{* *}\right)$ ile pozitif ve istatistiki olarak önemli korelasyona sahiptir. Araştırmada, tane verimi ile çiçeklenme gün sayısı arasında negatif $(r=0.162 *)$, bitkide tabla sayısı ile pozitif $\left(r=0.182^{*}\right)$ istatistiki olarak önemli ilişki belirlenmiştir (Çizelge 12). Pahlavani (2005) çiçeklenme gün sayısı ile tane verimi arasında pozitif, Nabloussi ve ark. (2008), Mousavi Ojaq ve ark. (2020) ise negatif önemli ilişkiler belirlemiştir. Gencer ve ark. (1987) bitki boyu ile tohum verimi ve yağ verimi arasında negatif; Eslam ve ark. (2010) ise pozitif ilişki olduğunu bildirmişlerdir. Omidi ve ark. (2012), Bahman (2015) ve Öz (2016) çalışmalarında tane verimi ile bitkide tabla sayısı arasında yüksek düzeyde pozitif ilişki belirlemişlerdir. Çamaş ve Esendal (2006) ile Eslam ve ark. (2010) tarafından yürütülen çalışmalarda yağ verimi ile yağ oranı arasında araştırma sonuçlarımıza benzer pozitif ilişki belirlenmiştir. 
Çizelge 12. İncelenen özellikler arasındaki korelasyon katsayıları.

\begin{tabular}{|c|c|c|c|c|c|c|c|c|}
\hline & $\begin{array}{c}\text { Tane } \\
\text { Verimi }\end{array}$ & $\begin{array}{c}\text { Yağ } \\
\text { Verimi }\end{array}$ & $\begin{array}{l}\text { Çiçeklenme } \\
\text { Gün Sayısı }\end{array}$ & $\begin{array}{l}\text { Bitki } \\
\text { Boyu }\end{array}$ & $\begin{array}{c}\text { Bitkide } \\
\text { Tabla } \\
\text { Sayısı }\end{array}$ & $\begin{array}{l}\text { Tabla } \\
\text { Çapı }\end{array}$ & $\begin{array}{l}1000 \text { Tane } \\
\text { Ağırlığı }\end{array}$ & $\begin{array}{c}\text { Yağ } \\
\text { Oranı }\end{array}$ \\
\hline \multicolumn{9}{|l|}{ Tane } \\
\hline Verimi & 1 & $0.512 * *$ & $-0.162 *$ & $-0.421^{* *}$ & $0.182^{*}$ & $0.401 * *$ & 0.052 & $0.299 * *$ \\
\hline \multicolumn{9}{|l|}{ Yağ } \\
\hline Verimi & & 1 & -0.135 & $-0.466 * *$ & 0.076 & $0.241 * *$ & 0.142 & $0.586 * *$ \\
\hline \multicolumn{9}{|l|}{ Çiçeklenme } \\
\hline Gün Sayısı & & & 1 & $0.313^{* *}$ & $-0.163 *$ & -0.133 & 0.075 & -0.072 \\
\hline \multicolumn{9}{|l|}{ Bitki } \\
\hline Boyu & & & & 1 & $-0.246 * *$ & $-0.187^{*}$ & 0.076 & $-0.417 * *$ \\
\hline \multicolumn{9}{|l|}{ Bitkide Tabla } \\
\hline Sayısı & & & & & 1 & $0.239 * *$ & -0.017 & -0.044 \\
\hline \multicolumn{9}{|l|}{ Tabla } \\
\hline Çapı & & & & & & 1 & 0.112 & 0.138 \\
\hline \multicolumn{9}{|l|}{1000 Tane } \\
\hline Ağırlığı & & & & & & & 1 & 0.204 \\
\hline \multicolumn{9}{|l|}{ Yağ } \\
\hline Oranı & & & & & & & & 1 \\
\hline
\end{tabular}

\section{Sonuç ve Öneriler}

Yağ bitkilerinin üretiminde gerek üretici gerek ise sanayici istekleri dikkate alındığında tane verimi kadar yağ verimi bakımından üstün genotiplerin kullanılması önem arz etmektedir. Çalışmada, Balcı ve Linas çeşitlerinin diğer hat ve çeşitlere oranla daha yüksek yağ oranı değerine sahip oldukları, birim alan tane ve yağ verimi bakımından ES-MUT-1 hattının ön plana çıktığı tespit edilmiştir.

Teşekkür: $\mathrm{Bu}$ makale TAGEM tarafından desteklenen TAGEM/TBAD/15/A04/P01/04 numaralı projenin çıktısı olup, çalışmaların yürütülmesinde verilen desteklerden dolayı teşekkür ederiz.

Çıkar Çatışması Beyanı: Makale yazarları aralarında herhangi bir çıkar çatışması olmadığını beyan ederler.

\section{Araştırmacıların Katkı Oranı Beyan Özeti:}

Yazarlar makaleye eşit oranda katkı sağlamış olduklarını beyan ederler.

\section{Kaynaklar}

Ada, R. 2013. Cluster analysis and adaptation study for safflower genotypes. Bulgarian Journal of Agricultural Science, 19: 103109.

Arslan, B. 2007. Assessing of heritability and variance components of yield and some agronomic traits of different safflower
(Carthamus tinctorius L.) cultivars. Asian Journal of Plant Science, 6: 554-557.

Arslan, B., Culpan, E. 2020. Melezleme ile geliştirilmiş bazı aspir (Carthamus tinctorius L.) genotiplerinin tarımsal ve teknolojik özelliklerinin belirlenmesi. Yüzüncü Yıl Üniversitesi Tarım Bilimleri Dergisi, 30:742-750.

Agasimani, C A., Patil, R. ve Hand Radder, G. E. 1997. Recent advances in agronomy of safflower (C. tinctorius L.) in India. IV th International Safflower Conference, 2-7 June, Bari, Italy, pp. 77-82.

Alizadeh, K. 2005. Safflower as a new crop in the cold drylands of Iran. Sesame and Safflower Newsletter, No.20 pp.

Anonim. 2004. Mutation breeding review. International Atomic Energy Agency (IAEA), No: 14, Wien, Austria.

Anonim. 2019. Bitkisel Yağ Sanayicileri Derneği, http://www.bysd.org.tr, Erişim tarihi: 15.01.2020.

Anonim. 2018. Türkiye İstatistik Kurumu, https://biruni.tuik.gov.tr Erişim tarihi: 15.01.2020.

Bahman, P.E. 2015. Effects of planting date on grain yield, yield components and oil content of safflower spring cultivars in Tabriz. Journal of Agricultural Science, 25(2): 155-164.

Bartlett, M.S. ve Kendall, D.G. 1946. "The statistical analysis of variances heterogeneity and the logarithmic transformation," JRSS Suppl 8: 128-138. 
Bayraktar, N. 1995. Üçüncü generasyon aspir (Carthamus tinctorius L.) melezinde tane verimi ve verim öğeleri. Tarla Bitkileri Merkez Araştırma Enstitüsü Dergisi, 4 (1): 23-29.

Beyyavaş, V., Haliloglu, H., Copur, O. ve Yılmaz, A. 2011. Determination of seed yield and yield components of some safflower (Carthamus tinctorius L.) cultivars, lines and populations under the semi-arid conditions. African Journal of Biotechnology, 10: 527-534.

Cazzato, E., Borazio, L., Corleto, A. 2001. Grain yield, oil content and earliness of flowering of hybrids and open- pollinated safflower in southern Italy. Vth International Safflower Conference, Wiliston, N.D., U.S.A., July 23-27, 185-189.

Çamaş, N., Esendal, E. 2006. Estimates of broadsense heritability for seed yield and yield components of safflower (Carthamus tinctorius L.). Hereditas, 143: 55-57.

Demirsoy, A. 1997. Kalıtım ve Evrim, Meteksan Yayınları, 8. Baskı, Ankara, S. 902.

Ekingen, H.R. 1991. Genetik, Uludağ Üniversitesi Ziraat Fakültesi Ders Notları No: 15, Bursa, S. 152.

Eslam, B.P., Monirifar, H. ve Ghassemi, M.T. 2010. Evaluation of late season drought effects on seed and oil yields in spring safflower genotypes. Turkish Journal of Agricultural Foresty, 34 (2010): 373-380.

Gawand, P. B., Reddyand, B. N. ve Tambe, S. I., 2005. Evaluation of productivity of safflower cultivars under moisture and nutrient management in rainfeed vertisols. $\mathrm{VI}^{\text {th }}$ International Safflower Conference, 610 June, Istanbul, Turkey, pp. 205-209.

Gencer, O., Sinan, NS. ve Gülyaşar, F. 1987. Aspir (Carthamus tinctorius L.)'de yağ verimi ile verim unsurlarının korelasyon ve path kat sayısı analizi üzerine bir araştırma. Çukurova Üniversitesi, Ziraat Fakültesi Dergisi, 2(2): 37-43.

Hang, A. N. ve Evans, D. W. 1985. Deficit sprinkler irrigation of sunflower and safflower. Agronomy Journal, 77: 588-592.

Johnson, R. C., Bergman, J. W. ve Flynn, C.R. 1999. Oil and meal characteristics of core and non-core safflower accessions from the USDA collection. Genetic Resources and Crop Evolution, 46: 611-618.

Khadeer, M. A. ve Anwar, S.Y. 1990. Induced mutation in the improvement of safflower (Carthamus tinctorious L). International Symposium on the Contribution of Plant
Mutation Breeding to Crop Improvement, 18-22 June, Vienna (Austria), 449-453.

Kıllı, F. ve Ermiş, H. 2009. Kahramanmaraş koşullarında farklı miktarlarda ve zamanlarda uygulanan azotun aspir (Carthamus tinctorius L.)' de tohum verimi, verim unsurları ve tohumun makro-mikro element içeriğine etkisi. Türkiye VIII. Tarla Bitkileri Kongresi, 19-22 Ekim, Hatay, s.107110.

Koutroubas, S. D. ve Papadoska, D. K. 2005. Adaptation, grain yield and oil content of safflower in Greece. $V I^{\text {th }}$ International Safflower Conference, 6-10 June, Istanbul, Turkey, pp. 161-167.

Köse, A., Onder. Ö., Bilir. Ö. ve Kosar. F. 2018. Application of multivariate statistical analysis for breeding strategies of spring safflower (Carthamus tinctorius L.) Turkish Journal of Field Crops, 23(1): 12-19.

Mousavi Ojaq, S.M., Mozafari, H., Sani, B. ve Jabbari, H. 2020. Evaluation of yield of safflower (Carthamus tinctorius L.) genotypes under semi-arid conditions. Plant Genetic Resources: Characterization and Utilization; 1-8.

Mozaffari, K. ve Asadi, A.A. 2006. Relationships among traits using correlation, principal components and path analysis in safflower mutants sown in irrigated and drought stress condition, Asian Journal of Plant Sciences, 5(6), 977-983.

Nabloussi, A., El Fechtali, M. ve Lyagoubi, S. 2008. Agronomic and technological evaluation of a world safflower collection in moroccan conditions. VII. International Safflower Conference, Wagga Wagga Australia.

Omidi, A.H., Khazaei, H., Monneveux, P. ve Stoddard, F. 2012. Effect of cultivar and water regime on yield and yield components in safflower (Carthamus tinctorius L.). Turkish Journal of Field Crops,17 (1): 10-15.

Öz, M. 2016. Aspir (Carthamus tinctorius L.)'de ekim zamanı, çeşit ve verim ilişkisi. Süleyman Demirel Üniversitesi Ziraat Fakültesi Dergisi, 11 (1):71-81.

Parameshwarappa, K.G. ve Meghannavar, R.D. 2001. Combining hybridization and irridation for enhancing genetic variability in early segregating generations of safflower crosses. $5^{\text {th }}$ International Safflower Conf. Williston North Dakota and Sidney, Montana USA, Pp:83-89.

Pahlavani, M.H. 2005. Some technological and morphological characteristics of safflower 
(Carthamus tinctorius L.) from Iran. Asian Journal of Plant Science, 4 (3): 234-237.

Patıl, S.A., Ravikumar, R.L., Prabhu, T.G. ve Parameshwarappa, G. 2001. Gamma radition Induced polygenic variation homozygous genotypes of safflower. $5^{\text {th }}$ International Safflower Conf. Williston North Dakota and Sidney, Montana USA, Pp:99-101.

Tonguç, M. ve Erbaş, S. 2009. Yerli ve yabancı orijinli aspir (Carthamus tinctorius L.) çeşit ve hatlarının verim ve verim öğelerinin belirlenmesi. Türkiye VIII. Tarla Bitkileri Kongresi, Hatay, 115-119.

Turan, Z.M. 1995. Araştırma ve Deneme Metotları, Uludağ Üniversitesi Ziraat Fakültesi Ders Notları No: 62, Bursa, S. 121.

Uslu, N. 1997. An improvement study in safflower by radiation induced mutations. Proceedings IV. International Safflower Conference, Bari-Italy, Pp: 248-251.

Zhang, Z. ve Chen, Y. 2005. Studies on adaptability of safflower germplasms in Xinjiang China. $\mathrm{VI}^{\text {th }}$ International Safflower Conference, 610 June, İstanbul, Turkey, pp. 132-139.

Weiss, E.A. 2000. Safflower. In: Oil seed Crops. 2nd ed. Blackwell Science, Oxford. 